\title{
A CLINICAL STUDY ON JUVENILE NASAL ANGIOFIBROMA IN A TERTIARY HOSPITAL OF KERALA
}

\author{
Beena Oommen ${ }^{1}$, Binu Raju George ${ }^{2}$ \\ ${ }^{1}$ Assistant Professor, Department of ENT, Government Medical College, Kozhikode, Kerala. \\ ${ }^{2}$ Assistant Professor, Department of ENT, Government Medical College, Kozhikode, Kerala.
}

ABSTRACT

\section{BACKGROUND}

Juvenile Nasal Angiofibroma is not an uncommon disease encountered in ENT practice. The surgical management is the mainstay of its treatment. CT scan and MRI and advent of Hypotensive anaesthesia has improved its pre-operative evaluation and lessened postoperative morbidity. The present study is to analyse retrospectively the clinical features and diagnostic features followup of 52 patients undergoing surgery in a tertiary hospital.

Aim- To study the incidence, mode of presentation and clinical course of the disease; to highlight the relevant investigations deemed necessary to make the diagnosis of juvenile nasopharyngeal angiofibroma.

\section{MATERIALS AND METHODS}

The demographic data of the patients was recorded; incidence of tumour with reference of age, sex and site of origin, mode of presentation, clinical findings, different types of investigation and different modalities of treatment, postoperative problems and also the followup details were extracted from the case records and analysed using standard statistical methods.

\section{RESULTS}

All patients were males and their age varied from 13 years to 38 years with a mean age of $19.4 \pm 2.6$ years; > 90\% of the patients were below the age of 25 years; $46.87 \%$ of the patients reported to the ENT Department with complaints of 6 to 12 months' duration and $37.50 \%$ less than 6 months. Progressive nasal obstruction and nasal bleeding were the main presenting symptoms in all the patients; recurrence was seen in 2 patients.

\section{CONCLUSION}

In totality, male incidence of this disease strongly indicates the need for chromosome studies of females with this diagnosis. CT scan is very important in finding out the extent of tumour and deciding the mode of treatment. Surgery is the treatment of choice. There is no single surgical technique, which solves all problems encountered.

\section{KEYWORDS}

Nasal Cavity, Nasopharynx, Tumour, Angiofibroma, Juvenile and Benign.

HOW TO CITE THIS ARTICLE: Oommen B. George BR, A clinical study on juvenile nasal angiofibroma in a tertiary hospital of Kerala. J. Evolution Med. Dent. Sci. 2017;6(24):2033-2037, DOI: 10.14260/Jemds/2017/443

\section{BACKGROUND}

The Angiofibroma is a benign tumour arising at the region of posterior nares or nasopharynx. It is a highly vascular, locally invasive, non-encapsulated tumour. ${ }^{1}$ Although, its local behaviour is the antithesis of benignity, this tumour is not malignant for it never metastasises nor does it infiltrate adjacent tissues. ${ }^{2}$ Since its early description as a nasal polyp in fourth century B.C by Hippocrates, it has earned repute as an enigmatic tumour. ${ }^{3}$ Angiofibroma, juvenile basal fibroma, bleeding, fibroma of adolescence are some of synonyms for this condition. ${ }^{4}$ The lesion produce its clinical effects during the adolescent years, so the adjective "Juvenile" is prefixed to the designation. Whether the tumour regresses with age and maturity, whether it possess a chance of malignant transformation are two debatable topics. ${ }^{5}$ The special importance lies in the fact that it spreads beyond the confines

Financial or Other, Competing Interest: None.

Submission 09-02-2017, Peer Review 08-03-2017,

Acceptance 15-03-2017, Published 23-03-2017.

Corresponding Author:

Dr. Beena Oommen,

Assistant Professor

Government Medical College,

Kozhikode, Kerala.

E-mail: drbeenaoommen@yahoo.com

DOI: $10.14260 /$ jemds $/ 2017 / 443$

\section{(c) $(1) \bigoplus$}

of nasopharynx. As a result of extensions, the tumour expands the nose, fills the antrum and in turn expands the cheek and at times invades the ethmoid and produces a "frog face deformity." It also erodes into the orbit and cranial cavity. ${ }^{6}$ The tumour has got fairly rapid, extensive growth and relatively great tendency to recur. The management of Angiofibroma is a therapeutic challenge even to the well-versed head and neck surgeons. What makes it a nearly dreaded disease is its propensity to produce massive haemorrhage, both spontaneous and peroperative. ${ }^{7}$ The present study attempts to analyse the clinical features, radiological signs and treatment adopted at Government Medical College Hospital.

\section{Aim of the Study \\ To study the incidence, mode of presentation and clinical course of the disease; to highlight the relevant investigations deemed necessary to make the diagnosis of juvenile nasopharyngeal Angiofibroma; outline the application and advantages of various surgical procedures in each particular case of Angiofibroma.}

\section{MATERIALS AND METHODS}

Between Jan 2003 and December 2007, 52 patients were admitted and treated in the Dept. of ENT, Medical College, Kozhikode. A retrospective study was conducted on these patients by scrutinising the case records and during followup. 


\section{Inclusion Criteria}

1. All the patients aged between 12 to 25 years were included.

2. All the patients presenting with nasal mass and history of bleeding from the nasal cavity were included.

3. Patients who have undergone surgery and whose records were available were included.

4. Patients with histopathological reports given as Angiofibroma are included.

\section{Exclusion Criteria}

1. Patients below 13 years and above 38 years were excluded.

2. Patients with negative reports of Histopathology as Angiofibroma were excluded. The demographic data of the patients was recorded; incidence of tumour with reference of age, sex and site of origin, mode of presentation, clinical findings, different types of investigation and different modalities of treatment, post-operative problems and also the followup were extracted from the case records and analysed using standard statistical methods. Histopathological examination of the excised tumour was undertaken. All patients had been operated in this institution itself. The data was collected in accordance to the proforma.

\section{RESULTS}

This is a retrospective study that covers a period of 5 years from Jan. 2003 to Dec. 2007. It includes 52 patients who presented to the Department of ENT of a Government Teaching Hospital, Kozhikode. The year wise distribution of Angiofibroma of the nasal cavity is shown as the incidence among all the ENT patients attending the ENT Department; $0.05 \%$ shown in the (Table 1 ).

\begin{tabular}{|c|c|c|}
\hline Year & $\begin{array}{c}\text { Total Number of } \\
\text { ENT Patients }\end{array}$ & $\begin{array}{c}\text { No. of Cases } \\
\text { Incidence }\end{array}$ \\
\hline 2003 & 17824 & $090.05 \%$ \\
\hline 2004 & 18965 & $100.05 \%$ \\
\hline 2005 & 19870 & $100.05 \%$ \\
\hline 2006 & 21653 & $120.05 \%$ \\
\hline 2007 & 23213 & $110.04 \%$ \\
\hline \multicolumn{2}{|c|}{$\mathbf{1 0 1 5 2 5}$} & $\mathbf{5 2 ~ 0 . 0 5 \%}$ \\
\hline Table 1. Showing Year Wise Distribution of Angiofibroma \\
patients attending the Hospital (n = 52)
\end{tabular}

Of these 52 patients, 2 patients were operated twice during this 5-year period. One patient was operated in 2003 and reoperated in 2005 and the other was operated in 2004 and 2006. All patients were males and their age varied from 13 years to 38 years with a mean age of $19.4 \pm 2.6$ years. The youngest was a 13-year-old boy, who had undergone a previous surgery for Stage IV Angiofibroma at the age of 8 years in this hospital. The eldest patient was 38 years old, who had undergone the surgery after a period of 5 years of nasal obstruction and epistaxis (Table 2).

\begin{tabular}{|c|c|c|}
\hline Age & No. of Pts. & Percentage \\
\hline $11-15$ Years & 10 & $19.23 \%$ \\
\hline $16-20$ Years & 18 & $34.61 \%$ \\
\hline $21-25$ Years & 12 & $23.07 \%$ \\
\hline $26-30$ Years & 09 & $17.30 \%$ \\
\hline > 30 Years & 03 & $05.76 \%$ \\
\hline \multicolumn{2}{|c|}{ Table 2. Showing the Age Wise Distribution of } \\
Angiofibroma Patients (n = 52)
\end{tabular}

This table shows that $>90 \%$ of the patients were below the age of 25 years. But the occurrence of tumour in 3 patients above the age of 30 years shows that it does not regress after the age of 30 years or it may appear de novo in older patients (Table 2). Progressive nasal obstruction and nasal bleeding were the main presenting symptoms in all the patients; 3 patients had cheek swelling. Other symptoms included recurrent nasal discharge, blocked ear sensation, headache, nasal tone of voice, snoring, etc. None of the patients had orbital symptoms or swallowing difficulty (Table 3).

\begin{tabular}{|c|c|c|}
\hline Presenting Symptoms & No. of Pts. & Percentage \\
\hline \multicolumn{3}{|l|}{ Nasal } \\
\hline 1. Nasal obstruction & 42 & $80.76 \%$ \\
\hline 2. Bleeding from nose & 41 & $88.46 \%$ \\
\hline 3. Nasal mass & 27 & $51.92 \%$ \\
\hline 4. Broadening of nose & 06 & $11.53 \%$ \\
\hline 5. Altered sense of smell & 11 & $21.15 \%$ \\
\hline 6. Nasal tone of voice & 14 & $26.92 \%$ \\
\hline 7. Headache & 10 & $19.23 \%$ \\
\hline \multicolumn{3}{|l|}{ Aural } \\
\hline 1. Blocked ear sensation & 08 & $15.38 \%$ \\
\hline \multicolumn{3}{|l|}{$\begin{array}{l}\text { Face } \\
\end{array}$} \\
\hline 1. Cheek swelling & 05 & $9.61 \%$ \\
\hline \multicolumn{3}{|l|}{ Eye } \\
\hline 1. Bulging of eye & 03 & $5.76 \%$ \\
\hline 2. Watering of eye & 03 & $5.76 \%$ \\
\hline 3. Defective vision & 02 & $3.84 \%$ \\
\hline \multicolumn{3}{|c|}{$\begin{array}{c}\text { Table 3. Showing the Presenting Symptoms } \\
\text { in the Patients }(n=52)\end{array}$} \\
\hline
\end{tabular}

In 34 patients, the main complaints were on the (L) nasal cavity, while 16 had (R) sided complaints. The duration of their symptoms varied from 6 months to 12 months in 28.84\% of the patients reported to the ENT Department and between 13 to 24 months in duration in $23.06 \%$ and less than 6 months in 21.15\% (Table 4).

\begin{tabular}{|c|c|c|}
\hline Duration of Symptoms & No. of Pts. & Percentage \\
\hline$<6$ months & 11 & $21.15 \%$ \\
\hline $6-12$ months & 15 & $28.84 \%$ \\
\hline $13-24$ months & 12 & $23.06 \%$ \\
\hline$>24$ months & 14 & $26.92 \%$ \\
\hline \multicolumn{3}{|c|}{$\begin{array}{l}\text { Table 4. Showing the Duration of Symptoms prior to } \\
\text { Presentation }(n=52)\end{array}$} \\
\hline
\end{tabular}

8 patients gave history of previous surgery and one patient was treated with radiotherapy for the same complaint. Duration between previous treatment and recurrence vary from 3 months to 6 years (Table 5).

\begin{tabular}{|c|c|c|}
\hline Mode of Treatment & No. & Age Groups \\
\hline Transpalatal surgery & 5 & $26-30$ Yrs. \\
\hline Transnasal surgery & 3 & 26 - 30 Yrs. \\
\hline Radiotherapy & 1 & > 31 Yrs. \\
\hline \multicolumn{3}{|c|}{$\begin{array}{l}\text { Table 5. Shows the Patients with Previous Treatment } \\
(n=09)\end{array}$} \\
\hline
\end{tabular}

Clinical examination revealed on Anterior Rhinoscopy, a firm reddish mass in 20 patients, a mass on Posterior Rhinoscopy in 21 patients; 05 patients presented with cheek swelling and 04 with a bulging mass in the Nasopharynx (Table 6). 


\begin{tabular}{|c|}
\hline ARS - Nasal mass: 20 \\
\hline PRS - Nasopharyngeal mass: 21 \\
\hline Bulge in NP roof: 06 \\
Cheek swelling: 05 \\
\hline Table 6. Showing the Examination Findings $(\boldsymbol{n}=\mathbf{5 2})$ \\
\hline
\end{tabular}

Only 42 CT scan reports were available among the 52 patients for analysis. In one patient, no nasal or nasopharyngeal lesion was detected. This was the case of recurrence after radiotherapy. CT scan revealed the recurrence in the pterygopalatine fossa. All patients were investigated with routine haemogram and urine analysis. CT scan was taken in all patients except two and MRI was taken in ten patients. These helped to find out the extension of the tumour and also helped in the selection of surgical approach (Table 8).

\begin{tabular}{|c|c|}
\hline CT Scan Findings- 42 Pts. & No. of Pts. \\
\hline Nasal Cavity & 19 \\
\hline Nasopharynx & 23 \\
\hline $\begin{array}{c}\text { Extra-nasopharyngeal extension with } \\
\text { multiple sinus involvement } \\
\text { combination: }\end{array}$ & \\
\hline Sphenoid & 19 \\
\hline Ethmoid & 9 \\
\hline Maxillary antrum & 7 \\
\hline Pterygopalatine fossa & 10 \\
\hline Infra-temporal fossa & 6 \\
\hline Cheek and temporal fossa & 3 \\
\hline Orbit & 1 \\
\hline Intracranial extension & 3 \\
\hline
\end{tabular}

Table 7. Showing the CT Scan and MRI Findings ( $n=52)$

In this study, the commonest extra-nasopharyngeal extension of the tumour was to the sphenoid sinus 19/52. All three cases with intracranial extension, middle cranial fossa extension were noted, but there was no intradural involvement. Even though orbital extension was noted in one patient, the peri-orbital tissue was intact and it did not affect the vision or eye movement. Depending on the CT scan findings, cases were staged according to the classification of Chandler et al (1984), (Table 8). All patients were treated surgically.

\begin{tabular}{|c|c|c|}
\hline & CT Scan & CT Scan + Per Op Findings \\
\hline Stage I & 07 & 07 \\
\hline Stage II & 24 & 24 \\
\hline Stage III & 09 & 09 \\
\hline Stage IV & 02 & 02 \\
\hline & $\mathbf{4 2}$ & $\mathbf{4 2}$ \\
\hline $\begin{array}{l}\text { Table 8. Showing the Comparison between CT Scan and } \\
\text { Per-Operative Findings to know the Specificity (n = 52) }\end{array}$ \\
\hline
\end{tabular}

Surgical approach depends on the size and extension of tumour. Hypotensive general anaesthesia was adopted to reduce the bleeding during the surgical removal of Angiofibroma from the patients. All patients were given a betablocker, either propranolol or atenolol on the preoperative day and a morning dose on the day of surgery. Instead of atropine, glycopyrrolate was used as the anticholinergic drug in the premedication. The blood pressure was maintained between $80-90 \mathrm{mmHg}$ systolic during the removal of the tumour mass. This was achieved by using titrated dose of Sodium Nitroprusside and halothane. This helped to achieve a bloodless field for surgery and minimum blood replacement per operatively. Most of the earlier studies showed a blood loss of 1.5 - 2 litres and each patient received 6 - 8 pints of blood during surgery. But in our studies, the average blood loss was only $500 \mathrm{~mL}$ and maximum blood replacement was 2 pints. Three of our patients did not require any blood transfusion. No external carotid ligation or embolisation was needed in any of our case. One of the patients who had undergone transnasal excision of the tumour developed recurrence after 2 years and he was re-operated by transpalatal approach. One of the patients with intracranial extension underwent combined transpalatal and sublabial excision of the tumour developed recurrence and was re-operated by Weber Ferguson's approach. Both of these patients are symptom free now (Table 8).

\begin{tabular}{|c|c|}
\hline Transpalatal & 27 \\
\hline Sublabial & 08 \\
\hline Combined & 08 \\
\hline Weber Ferguson's & 06 \\
\hline Transnasal & 03 \\
\hline Table 9. Showing the various Surgical approaches \\
Adopted (n = 52)
\end{tabular}

Wilson's transpalatal approach was used for tumours confined to nasopharynx and paranasal sinuses. In extensive extension to pterygopalatine, tumour in the nasopharynx removed by transpalatal approach and the lateral extensions removed by a sublabial route. In cases with extensive lateral extension to infratemporal fossa with or without intracranial involvement, a midfacial degloving approach or Weber Ferguson's approach gave a good exposure for tumour clearance. The average blood loss was $500 \mathrm{~mL}$ and it was corrected with whole blood transfusion; 3 patients did not require any blood replacement. There was no correlation between the age of the patient and vascularity of the tumour. Also, bleeding has no relation with the staging of the disease. Probably, the judicious use of hypotensive anaesthesia helped to control the blood loss and also it provided a bloodless field for surgery. Nasal pack removed after 24 - 48 hours.

\begin{tabular}{|c|}
\hline $\begin{array}{c}\text { No complication } 39 \\
\text { Meningitis } 01\end{array}$ \\
\hline Palatal gap 05 \\
\hline Synechiae 07 \\
\hline Table 10. Showing the Post-Op Complications $(\boldsymbol{n}=\mathbf{5 2})$ \\
\hline
\end{tabular}

There was no major complication except one patient developed meningitis, but fully recovered with medical treatment; 5 patients had small palatal gap, which was spontaneously healed; 7 patients had synaechiae in the nasal cavity, but it does not interfere with normal breathing in any of them. The remaining 39 patients did not show any postoperative complications (Table 9).

\section{DISCUSSION}

In this retrospective study of 52 cases, the peak incidence of disease was noticed between 16 - 20 years. The mean age was $19.4 \pm 2.6$ years. Martin, Ehrlich and Abels ${ }^{8}$ (1948) reported a series of 29 cases with an average of 16 years. New G. B. and Figi F. A. (1925) ${ }^{9}$ in 51 cases reported an average of 15.1 years. Shaheen ${ }^{10}$ (1930) in reviewing 58 cases stated the most common age to be between 15 - 25 years (age varied from 2 - 
70 years). In our study also more than $77 \%$ of patients were between 11 - 25 years; 12 (> 23\%) patients were above the age of 25 years. This denotes that spontaneous regression after 25 years do not occur in Angiofibroma. Typical cases have been noted by Conley and Healy ${ }^{11}$ (1968), who have recorded a 79year-old male. All 52 cases were males, which goes in accordance with many studies. But Figi and New ${ }^{9}$ (1992) reported an incidence of $7 \%$ in females. Also Shaheen ${ }^{10}$ (1930) reported $8 \%$ incidence in females. Wilson and Hanefee ${ }^{12}$ in 1969 mentioned 2 female cases, but later they were histologically suggested the final diagnosis of haemangioendothelioma for one and adenoid hypertrophy for the other. The main complaints were nasal obstruction and epistaxis in the present study. The duration of symptoms varied from 1 month to 5 years. There was no correlation between the duration of illness and extend of tumour. One patient with extensive lateral extension gave a short history of 1 month duration. The cheek extensions are clinically apparent and are found to occur through the lateral wall of nasopharynx. After destroying the pterygoid plates, the tumour extend to pterygopalatine fossa winding round the posterior surface of maxilla through pterygomaxillary fissure, thus entering the cheek. Martin ${ }^{8}$ described an alternate route to cheek by anterior extension of tumour to nasal fossa and then by transmaxillary extension to cheek destroying medial and anterolateral walls of maxilla. In this study, all patients had lateral extension through destruction of pterygoid plates.

\begin{tabular}{|c|c|c|}
\hline Clinical Features & Apostle et al & Present Study \\
\hline Nasal Obstruction & $90 \%$ & $80.76 \%$ \\
\hline Bleeding & $80 \%$ & $88.46 \%$ \\
\hline Cheek Swelling & $30 \%$ & $10 \%$ \\
\hline \multicolumn{2}{|c|}{ Table 11. Showing Comparative Study } \\
\hline
\end{tabular}

$17.30 \%(09 / 52)$ patients gave a history of previous treatment in this study. But the time interval of recurrence varies from 3 months to 6 years. In 9 patients (17.30\%) the tumour was confined to nasopharynx and $82.69 \%$ had extra nasopharyngeal extension of the tumour, similar to Jones et $\mathrm{al}^{13}(82.5 \%)$. Thus, the present study report and of Jones et al (1986) are very similar in extra nasopharyngeal extension. Intracranial extension occurs in $10 \%$ of cases. Jones et al have given a much higher incidence $(30 \%)$. Krekonien and Keto ${ }^{14}$ (1976) gave an incidence of $10 \%$ - 20\% intracranial extension, which favours the finding in our study. According to Chandler's ${ }^{6}$ classification (1984), (based on 23 cases) $40 \%$ come in Stage II, 30\% in Stage III, $20 \%$ in Stage I and $10 \%$ in Stage IV (Table 11).

\begin{tabular}{|c|c|c|c|c|}
\hline \multirow{2}{*}{} & \multicolumn{4}{|c|}{ Stage } \\
\cline { 2 - 5 } & I & II & III & IV \\
\hline Chandler6 & $10 \%$ & $20 \%$ & $45 \%$ & $25 \%$ \\
\hline Present Study & $20 \%$ & $40 \%$ & $30 \%$ & $10 \%$ \\
\hline Table 12. Showing the Comparative Study with Chandler's \\
Study (n= 52)
\end{tabular}

In this study, 09 patients presented with history of previous surgery or radiation therapy. Two patients reported in this series showed recurrence during the study period itself. Overall, recurrence rate is (9/52) $17.30 \%$ (Table 12 ).

\begin{tabular}{|c|c|}
\hline Close et al (1989) & $17 \%$ \\
\hline Jones et $\mathrm{al}^{14}(1986)$ & $24 \%$ \\
\hline English et al (1972) & $25-50 \%$ \\
\hline Present Study- 09/52 & $17.30 \%$ \\
\hline
\end{tabular}

No cases of spontaneous regression noted in this study and also no sarcomatous transformation occurred in any of our case. Batsakis ${ }^{15}$ in 1955 reported a sarcomatous change in the primary tumour of Angiofibroma. Harma in 1972 indicated a 2-year interval after surgery without recurrence indicated cure. But in this study recurrence occur even after 6 years was $17.30 \%$. So a longer followup period is required to conclude as a cure. In suspected cases, CT scan is a must to diagnose early recurrence. Histopathology of all the 52 tumours excised revealed a fibrocellular stroma with spindle cells and haphazard arrangement of collagen interspersed with an irregular vascular pattern.

\section{CONCLUSION}

Juvenile Nasopharyngeal Angiofibroma is a highly vascular, benign yet locally invasive tumour. It is prevalent in adolescent males, similar tumours seen in females are not this particular disease, and totality of male incidence of this disease strongly indicates the need for chromosome studies of females with this diagnosis. CT scan is very important in finding out the extent of tumour and deciding the mode of treatment. Surgery is the treatment of choice. There is no single surgical technique, which solves all of the problems encountered. The lateral wall of nasopharynx, region of sphenopalatine foramen found to be the commonest site of origin.

\section{REFERENCES}

[1] Apostel JV, Frazell EL. Juvenile nasopharyngeal angiofibroma. A clinical study. Cancer 1965;18:869-78.

[2] Brunner H. Nasopharyngeal fibroma. Annals of Otology, Rhinology and Laryngology 1942;51:29-63.

[3] Batsakis JG. Tumours of the head and neck. Baltimore Williams and Wilkins Co 1974:174-218.

[4] Bhatia ML, Mishra SC. Intracranial extension of juvenile angiofibroma of the nasopharynx. J Laryngol Otol 1967;81(12):1395-403.

[5] Biller HF, Sessions DG, Ogura JH. Angiofibroma: a treatment approach. Laryngoscope 1974;84(5):695706.

[6] Chandler JR, Goulding R, Moskowitz L, et al. Nasopharyngeal angiofibromas: staging and management. Ann Ortol Rhinol Laryngol 1984;93(4 Pt 1):322-9.

[7] Chatterjee P, Soni NK, Chattery S. A few points in the management of JNA. J Laryngoil Otol 1984;98:489-92.

[8] Martin H, Ehrlich HE, Abels JC. Juvenile nasopharyngeal angiofibroma. Annals Surgery 1948;127(3):513-36.

[9] Finerman WB. Juvenile nasopharyngeal angiofibroma in the female. AMA Arch Otolaryngol 1951;54(6): 620-3.

[10] Shaheen HB. Nasopharyngeal fibroma. J laryngol Otol 1930;45:259-64.

[11] Conley J, Healy WV, Blaugrund SM, et al. Nasopharyngeal angiofibroma in juvenile. Surgery Gynecology \& Obstetrics 1968;126(4):825-37. 


\section{Jemds.com}

[12] Wilson GH, Hanafee WN. Angiographic findings in 16 patients with juvenile nasopharyngeal angiofibroma. Radiology 1969;92(2):278-9.

[13] Jones GC, DeSanto LW, Bremer JW, et al. Juvenile angiofibromas. Behavior and treatment of extensive and residual tumours. Arch Otolaryngol Head Neck Surg 1986;112(11):1191-3.

\section{Original Research Article}

[14] Krekorian EA, Kato RH. Surgical management of nasopharyngeal angiofibroma with intracranial extension. Laryngoscope 1977;87(2):154-64.

[15] Harma RA. Nasopharyngeal angiofibroma: a clinical and histopathological study. Acta: Otolaryngol Stockh 1958;146:1-76. 